\title{
POESÍA AUTOETNOGRÁFICA DE PEDRO ALONZO RETAMAL, ANTROPÓLOGO DE SÍ MISMO*
}

\author{
Iván Carrasco \\ Universidad Austral de Chile \\ icarrasc@uach.cl \\ RESUMEN / ABSTRACT
}

La finalidad de este trabajo es hacer una relectura desde una perspectiva intercultural del libro de poemas epu mari quiñe ülcatun (veintiún cantos o poemas) de Pedro Alonzo Retamal, para destacar una dimensión no estudiada de su escritura: el uso de un modelo textual de orden antropológico, el discurso autoetnográfico. A pesar del manejo seguramente intuitivo de este elemento, ello contribuye a configurar la imagen de un "antropólogo de sí mismo", pues esta clase de textos remite a la cultura del sujeto que enuncia su identidad.

Palabras clave: discurso autoetnográfico, poesía etnocultural mapuche, Pedro Alonzo Retamal, interculturalidad, mapudungun.

The purpose of this paper is to reread from a book of poems intercultural epu ülcatun Quine mari (twenty songs or poems) by Pedro Alonzo Retamal, to highlight an unstudied dimension of his writing: the use of a textual model of order anthropological autoethnographic discourse. Although certainly intuitive handling of this item, it helps shape the image of an "anthropologist of self", as this type of text refers to the individual's culture which sets their identity.

KEY WORDS: autoethnographic discourse, Mapuche ethnocultural poetry, Pedro Alonzo Retamal, intercultural, Mapudungun.

Este trabajo forma parte de los proyectos Fondecyt 1100662, Investigador Responsable: M. Claudia Rodríguez Monarca, del cual soy Coinvestigador, y Fondecyt 1100344 del que soy Investigador Responsable. Corresponde a una versión corregida de la ponencia presentada en el Congreso Internacional de Lenguas y Literaturas Indoamericanas, Jornadas de Lengua y Literatura Mapuche, Temuco, UFRO, 14-16 noviembre 2012. 


\section{FUNDAMENTOS}

Junto con los rasgos propios de la poesía occidental (versificación, retórica, géneros, estrofas, emotividad del sujeto enunciativo, temas característicos, registros diversos...) y de las estrategias textuales aportadas por la intertextualidad manejada por los escritores mapuche (codificación plural, enunciación sincrética o intercultural, intertextualidad transliteraria, enunciado intercultural, Carrasco, I. Textos 5-15), en los poemas de Pedro Alonzo Retamal he podido observar la presencia de un tipo de discurso autoetnográfico. Como se sabe, la etnografía es la descripción detallada de un aspecto específico de una cultura ajena, conocida y explicada a partir de la experiencia directa por investigadores preparados profesionalmente para describirlas mediante la escritura. Por ello, la autoetnografía, llamada por algunos antropólogos autoetnología, es la autoobservación, el estudio de la cultura propia del sujeto que enuncia, en otras palabras, del que habla, piensa, sueña, escribe, canta, recita, en la escritura, en este caso, en el texto poético.

Este modo de trabajar ha aparecido en el ámbito de la antropología y de otras disciplinas de las ciencias humanas y ha invadido con rapidez distintas áreas (literatura, psicología, pedagogía, filosofía, historia, metodología de la investigación científica, artes visuales, construcciones sociales, metodologías alternativas en los estudios etnográficos, etc.), manejando tecnologías, metodologías y objetivos variados, pero sobre una base común: un tipo de escritura y de texto que establece la posibilidad a un artista o investigador de ser sujeto y objeto de una observación cultural, de su propio estudio.

Autores como Coffey, Ellis, Blanco, Bouchner, Reed-Danabay, MonteroSieburth, Smith, Wall, Ruiz Trejo, Blanco, Russell, Scribano, De Sena, Augé, para nombrar algunos, le han dado vida mediante investigaciones, jornadas, escritos, diálogos, mostrando algunas de sus posibilidades, problemas y conexiones interdisciplinarias.

Augé (46-50) reconoce la existencia de dos tipos de estudio en referencia a la que llama doble etnología: una autoetnología cuyo objeto sería el propio observador o su entorno inmediato y la aloetnología, el estudio de los otros, de sociedades, culturas y sujetos diferentes. Esto permitiría apreciar la exterioridad del objeto en función de su distancia geográfica, cultural, social respecto al punto de observación o al observador. Valorando las posibilidades de intercambio entre observadores de su propia, análoga o distinta cultura, o la visión de observadores externos, el hecho de no estar implicado o no ser implicable o lo menos posible en las situaciones que se observan, o la idea que 
el objeto de dicha visión "debería ser una cultura común a todos los miembros de un grupo y de la que estuvieran tan profundamente integrados que fueran capaces por ellos mismos de captarla en su totalidad y de expresarla en su complejidad" (Augé 46), es explicable y comprensible que sin ser etnólogos, los escritores pueden describir su cultura, desarrollando al mismo tiempo semblanzas de ella también para lectores de diversas culturas.

Observar a otro, un ser, entidad o documento distinto, étnica o culturalmente, es hacer etnografía. Observarse a sí mismo, a la propia comunidad, cultura o literatura, es hacer autoetnografía, el tipo de investigación que tiene como objeto al propio observador o su cultura. Es lo que hace Pedro Alonzo, de cuya obra destacaremos algunos cuadros interpretados desde una perspectiva intercultural, que sin duda es el modelo más apropiado para leer una textualidad que es resultado de la interacción entre la cultura occidental y una cultura indígena. Para ello tomaré como base la teoría de la comunicación intercultural de Miquel Rodrigo A. (9-80) y mis propias observaciones al respecto (Carrasco, I., Interculturalidad 63-68). Rodrigo (12) entiende la comunicación intercultural como la comunicación entre las personas que poseen referentes culturales tan distintos que se autoperciben como pertenecientes a culturas diferentes. En relación con la diversidad cultural se produce un fenómeno de atribución identitaria y en los contactos interculturales se realiza una percepción selectiva que destaca las diferencias, lo que permite construir con más facilidad las identidades.

Desde otro ángulo, un escritor y estudioso colombiano, Miguel Rocha, ha usado la expresión autoetnografía en dos sentidos distintos, uno análogo a lo que consideramos etnoliteratura en el campo de la investigación mapuche (la representación escrita de la oralidad indígena, valorada como texto artístico en sentido occidental, por medio de una lengua de origen europeo) y el otro distinto, literatura escrita por indígenas con influencia antropológica para sí mismos y para lectores extranjeros, perspectiva auto-etnográfica que caracterizó los trabajos etnoliterarios durante el siglo XX en Colombia según su opinión (Rocha, Palabras 21):

A mi modo de ver, utilizar el prefijo etno es útil si nos referimos a las obras transcritas bajo el enfoque etnográfico, es decir, la escritura científica sobre sociedades tradicionales que, por sus propios valores e intereses culturales y/o excepcionalmente por su falta de acceso a un tipo de tecnología de fijación fonética -la escritura es una tecnología-, colaboraron o aún colaboran como informantes, usualmente sin que ellos mismos escriban, editen y lean la producción 
gráfica de ese llamado conocimiento científico social. Diferente es el caso de la etnoliteratura propia, escrita auto-etnográficamente por miembros de las comunidades que recibieron formación o influencia antropológica: los ejemplos más comunes se encuentran en algunos capítulos de los planes de vida, las cartillas de etnoeducación y en la obra de autores como Alberto Juajibioy Chindoy" (Rocha Pütchi 51; las cursivas son mías).

Los escritores mapuche y de otros sectores de América, teniendo como destinatario inevitable al huinca, al extranjero, y a su propia condición, cultura y discursos como material de intercambio, no cesan de explicarle al otro quiénes son, cómo es su cultura, sus memorias, sus territorios, cuáles son sus semejanzas y diferencias, sus afectos y sus odios. Por ello, construyen discursos autoetnográficos en muchos procesos de comunicación intercultural, tal vez a veces sin saberlo y a veces con extrema conciencia, a veces en estilos y textos literarios convencionales de la cultura occidental, otras en sus propios textos etnoculturales como Chihuailaf, Lienlaf, Paredes Pinda, Pedro Alonzo, entre otros.

Toda la escritura literaria de origen, carácter o cultura indígena en América es un largo discurrir sobre la propia cultura, mezclada con otros temas, una interrogante desde y sobre los orígenes, la memoria, la nostalgia, la tradición, la conquista, la interculturalización creciente. Por ello, como sus cultores han sido entrevistados durante mucho tiempo por los misioneros, los lingüistas, los historiadores, los periodistas, los profesores, los estudiantes, los escritores, incluso por personas comunes, en su lengua o en otra, o en interlenguas parciales, han internalizado con interés o preocupación, objetivos de liberación, colaboración o autoexhibición, el modelo del texto etnográfico, que han convertido en muchos casos en un texto autoetnográfico.

La escritura etnográfica como tipo de discurso, quizás menos sofisticada que la que practican antropólogos y arqueólogos contemporáneos, de corrientes postmodernas principalmente, ha sido cultivada por cronistas e historiadores de Indias europeos y criollos desde hace mucho tiempo. Los primeros en escribirla fueron indígenas, por lo que ha enfatizado López-Baralt (20) que el carácter etnográfico del género de la crónica de Indias ha fundado nuestras letras latinoamericanas, además de haberse adelantado a la antropología y contribuido a su constitución.

El origen de las relaciones entre literatura y antropología y, por tanto, de la aparición en el siglo XX de la literatura antropológica contemporánea, se puede hallar sobre todo en la crónica de Indias de carácter referencial, jurídico, 
geográfico, en las historias coloniales, en los documentos de carácter etnográfico de autores de origen, lengua y/cultura indígena, pero también de escritores y pensadores europeos, tal el mismo Cristóbal Colón que inició el proceso de ficcionalización o literaturización de América, como señaló Arrom, que luego dio lugar a las utopías de Moro y Campanella, al relativismo cultural de Montaigne. Este proceso doble, por una parte, de imbricación de textualidades indígenas, europeas, africanas y criollas en la escritura hispánica, por otra, de problemáticas, estilos, géneros y formas de enunciación característicos de la literatura, la antropología y la arqueología, con otras ciencias, la filosofía, la historia, la comunicación social, ha tenido grandes figuras como Claude Lévi-Strauss desde una perspectiva, José María Arguedas desde otra, además de una selectiva lista de autores hispanoamericanos elaborada por López-Baralt y una lista heterogénea y actual de autores llamados indígenas de distintos países de América mestiza (Perú, Paraguay, Chile, Colombia, Estados Unidos, México, Guatemala, Brasil, etc.). Pané, Inca Garcilaso y Guaman Poma "aportaron los primeros bloques que sostienen el edificio de lo que hoy conocemos como antropología, sentando a la vez las pautas para una trayectoria que nuestras letras, entonces germinales, aún no han abandonado" (López-Baralt 29).

Las sociedades que tienen discursos científicos tienden a imponerlos o enseñarlos a las sociedades adyacentes o conectadas de alguna manera. En el caso de sociedades y culturas que se comunican escasamente con las otras, se tiende a considerar que realizan procesos intraculturales preferentemente, mientras que a las que desarrollan mayores interacciones e intercambios se las considera interculturales, lo que implica el deseo de conocer, comunicarse y convivir con los otros, de aceptar y compartir, transmitir y fomentar conocimientos, lenguajes, artes, entretenciones, trabajos, religiones, tantas cosas más.

Las sociedades occidentales que se instalaron en América mediante la invasión y la colonización se han preocupado de establecer nexos intelectuales y cognitivos, por lo general asimétricos, con las sociedades y culturas indígenas y de emplear sus conocimientos y disciplinas científicas en este proceso. De este modo, se han ido desarrollando en territorios y asentamientos indígenas disciplinas de la ciencia, el arte, el conocimiento, a veces aprendidas en forma sistemática mediante la educación, otras de modo intuitivo o experiencial, lo que ha posibilitado no solo el dominio y la colonización desde perspectivas occidentales, sino también el aprendizaje de estrategias, contenidos y proyectos de liberación y descolonización. Todo 
esto ha desarrollado intensas relaciones interculturales, y por ello, muchos objetos de estudio principales de los viajeros han sido los textos de grupos indígenas que los cientistas sociales han incluido en sus estudios en cuanto documentos: géneros referenciales, como cartas, autobiografías, confesiones, testimonios, etc., junto a leyendas, cuentos, novelas, poemas, aun sabiendo que la sociedad de origen los considera textos de otra condición.

Así se ha ido desarrollando lo que más tarde se llamaría etnología y luego antropología, posterior al fenómeno llamado modernamente literatura, que influyó decididamente en la concepción de esta nueva disciplina social. A tal extremo ha llegado esta interacción entre antropología y literatura que Cl. Lévi-Strauss escribió un valioso texto ambivalente, Tristes Trópicos, que es simultáneamente un diario de viaje antropológico y literario, un relato etnográfico y novelesco, que daría origen a una interdisciplina, la antropología literaria (o poética, como ha sido llamada en Chile por una serie de jóvenes -entonces- estudiantes y profesores de la Universidad de Chile).

En ese marco aparecieron, sin duda, las etnoliteraturas, las literaturas interdisciplinarias e interculturales y sus conexiones de éstas con la etnografía. Desde los albores de nuestra América, la antropología y la literatura se han dado la mano, ha escrito hermosamente López-Baralt. De modo confluyente es necesario considerar que, siendo el objeto de estudio de las disciplinas antropológicas la problemática del otro o la otredad, no se puede obviar que ella es más o menos equivalente para europeos e indígenas y no exclusiva de los invasores.

En nuestro país, las relaciones interculturales debieran ser de antigua data, debido a la existencia de grupos indígenas desarrollados y con alta sociabilidad, como se puede ver, por ejemplo, en los variados indigenismos de nuestras lenguas nacionales y en los nombres de lugares. No obstante, factores decisivos y de especial impacto fueron la invasión hispánica y sus efectos, los sucesivos procesos de colonización y las interculturalidades posteriores. La enorme diferencia de culturas, el alto grado de desarrollo científico y filosófico europeo, su experiencia en viajes, sociedades variadas y su interés por el conocimiento propio y ajeno, produjo una interacción compleja, contradictoria y conflictiva.

En muchos textos mapuche, poéticos de carácter político o de denuncia social, así como en otros de orientación metadiscursiva y de carácter público, aparece la necesidad de dirigirse a un destinatario huinca, quien a veces lo ha estimulado a desarrollar sus propios discursos en los que pueden explicitar lo que ya saben (la entrevista periodística o antropológica), el pensamiento intercultural 
se desarrolla en ambos sectores: la necesidad de explicar conceptualmente su actividad artística se ha derivado de una prolongada situación de contacto intercultural con la sociedad huinca. Tomar conciencia de esta situación le ha permitido a los mapuche no solo adecuarse existencialmente a la forzada convivencia interétnica que no pueden evitar, sino también transformarla en un efectivo diálogo intercultural que les permite sobrepasar los vínculos de dominación o aislamiento. Como han coexistido en un mismo territorio con los huinca (modo en que los mapuche nombran a los extranjeros y a los no mapuche en su territorio) durante un tiempo apreciable, sin perder los patrones básicos de su propia cultura y sin aislarse de la cultura foránea establecida, por lo cual su comunicación cotidiana y literaria está marcada por un fuerte carácter intercultural.

Entre las diversas estrategias textuales aprendidas, modificadas o creadas por los escritores mapuche, ha aparecido la configuración de una especie de texto autoetnográfico que estamos explicando, puesto que en su horizonte de expectativas se encuentra un sistema de recepción intercultural, formado por lectores y enciclopedias culturales (Eco 27: 53) de carácter europeo, indígena y chileno. Diversos poetas como Chihuailaf, Lienlaf, Colipán, Huenun, Paredes Pinda, por ejemplo, y narradores como Ruth Fuentealba Millaguir, Graciela Huinao o los que forman parte de la colección del ILV, en vez de usar como modelo de sus textos de intención artística géneros literarios tradicionales, han preferido combinarlos o reemplazarlos, voluntaria o instintivamente, por textos autoetnográficos debido a la recepción prevista de personas de distinto origen y formación etnocultural que leen o escuchan en español y/o mapudungun y los bilingües expertos de ambas culturas.

De este modo, usan estrategias textuales como una actitud testimonial de formar parte de una comunidad mapuche, citando textos correspondientes a poetas propios (como Sebastián Queupul de quien se citan versos o estrofas), o de relatos de la tradición (sobre todo de Tren-Tren y Kai-Kai), o de sujetos que destacan la asunción de los valores societarios, mitos y rebeliones, el sentimiento de formar parte de la naturaleza viva, o de presentar expresamente documentos etnográfico-históricos de una comunidad determinada evaluados desde su óptica mapuche o mapuche-huilliche, como en la obra historicista de Colipán por ejemplo. Estos textos, aun siendo ficticios como todo discurso literario, permiten representar o expresar sentimientos verídicos, informaciones o datos autobiográficos y testimoniales efectivos, elementos prevalecientes en los discursos de antropólogos o arqueólogos, como la otredad, la invasión, la colonización, la deculturación, los viajes, la ruptura de 
la familia, la interculturalidad, incluso la utopía del diálogo mapuche-huinca. Para ello, otros como ancianos y ancianas sabios y vinculados con los rituales y misterios de su religión, como la poeta-machi Adriana Paredes Pinda en sus Tesis de 2008 y 2013, hacen uso del "rakiduam" (conocimiento antiguo, ancestral, secreto, sagrado, de los ancianos y agentes del culto religioso de las distintas comunidades mapuche).

A pesar de la variedad de perspectivas y objetos de estudio descubiertos en la literatura mapuche, aún no se ha analizado el manejo del discurso autoetnográfico como modelo implícito de escritura poética. Aunque ha sido utilizado por poetas prestigiosos, que han alcanzado lugares de privilegio en la sociedad mapuche, chilena e internacional, por razones de justicia histórica y literaria examinaré el uso que ha hecho de él un escritor poco conocido, nunca invitado ni premiado, Pedro Alonzo Retamal. Alonzo es uno de los iniciadores de la poesía etnocultural mapuche moderna junto a Sebastián Queupul Quintremil, en la Frontera, y José Santos Lincomán, en Chiloé. También ha sido precursor en la búsqueda de la actitud de reetnización en la cultura y sociedad mapuche característica de diversos escritores y escritoras mapuche actuales, como Rayen Kvyeh, por ejemplo. Entiendo por reetnización un proceso sistemático, voluntario o espontáneo de algunos hombres y mujeres mapuche que, habiendo nacido en algunas comunidades rurales, pueblerinas y citadinas y aprender por ende alguno de los dialectos que constituyen la lengua mapuche, el mapudungun, y haber vivido en su cultura, se han ido al pueblo o la ciudad por razones diversas y perdido los valores, hábitos y costumbres. Pero, más tarde, por una motivación personal o grupal, se dedican en forma sistemática a revivir las costumbres, la lengua y la forma de vida mapuche. Es un fenómeno vinculado a lo que llama Fishman retradicionalización, es decir, una instancia de búsqueda en el pasado en fuentes de un saber anterior para reconstruir una tradición; García (53-55) lo retoma como mecanismo sociocultural de articulación y reelaboración del pasado, que opera como un mecanismo de organización discursiva y metadiscursiva en función de reafirmación de lo propio y de refuerzo identitario que convertiría el espacio textual en un territorio simbólico o frontera desde donde se marca la diferencia cultural. 


\section{EL DESARROLLO DE LA LITERATURA MAPUCHE}

Lo que se llama "literatura mapuche" es un proceso en curso, realizado en interacción por creadores mapuche (o productores de objetos de comunicación literaria, Schmidt 199-200) y agentes de transformación de los objetos de comunicación literaria, es decir, críticos e investigadores literarios de carácter no mapuche por lo general en un proceso de colaboración y reciprocidad que se inició con la colonización y persiste hasta hoy. Como "todas las culturas poseen algún tipo de tradición, actividad y tradición artística" (Grebe 19), los mapuche han valorado textos narrados (epeu) y cantados ( $\ddot{u} l)$ entre otros tipos de discurso, poseedores de ciertas características conservadas en su memoria, que han sido considerados etnoliteratura; H. Carrasco (10-12) entiende como etnoliteratura el conjunto o sistema de manifestaciones textuales de carácter verbal consideradas como propias por el pueblo que las produce, que cumplen funciones variadas en la vida de las comunidades. Se desarrolla en la tradición oral e implica una metalengua específica, contextos socioculturales, determinadas situaciones pragmáticas. En tanto orales, los textos están conformados por una cantidad indefinida de versiones y variantes, son productividades interpersonales y retradicionalizadas, se generan en la lengua materna y se comunican en la lengua de contacto con otras culturas.

Como la literatura se define por la escritura, debieron pasar muchos años para que en su proceso de interculturación algunos profesores y poetas aprendieran la lengua y la literatura españolas, principalmente reiterando los textos poéticos hispánicos y chilenos e integrándose con escaso éxito o reconocimiento al sistema de la poesía nacional: Guillermo Igaymán, Emilio Antilef, Antonio Mulato Ñunque, Martín Alonqueo, los más nombrados; no menciono por ello como poeta a Calvún, informante de Lenz. Años más tarde, en la década de los 60, Queupul, Alonzo y Santos Lincomán iniciarán una literatura propiamente mapuche, pero ya intercultural, junto a escritores de origen extranjero y de Chiloé, tales como Vulliamy, Troncoso, Riedemann, Muñoz, Caicheo, Torres, García, Mansilla.

Hay varios momentos en la construcción de la literatura mapuche mediante la interacción y la colaboración, en que los huincas han motivado, enseñado, recopilado, editado, antologado, etc., hasta llegar a ser compañeros en rutas confluyentes. Tal vez el primer huinca que tuvo sensibilidad para reconocer el carácter distinto de una clase de textos orales mapuches y su cercanía al arte verbal fue Francisco Núñez de Pineda y Bascuñán que en su libro El Cautiverio feliz incluyó un fragmento de canto $(\ddot{u} l)$ de un amigo lonco (persona 
importante, con liderazgo y buena situación socioeconómica en la comunidad mapuche). Más adelante, el misionero jesuita P. Bernardo Havestadt recopiló 4 cantos de machi en su obra Chilidug 'u sive Res Chilense de 1777. Luego, el lingüista Rodolfo Lenz delimitó los géneros básicos de la etnoliteratura mapuche llamada "literatura araucana" en 1897, obra continuada y superada por Fray Félix José de Augusta, sacerdote capuchino, con la ayuda del P. Sigifredo de Franhäusl, en sus Lecturas Araucanas de 1934, mientras otro misionero, Ernesto Wilhelm de Moesbach, editaba la autobiografía de su amigo Pascual Coña. De ahí en adelante aparecerá una serie de estudiosos del mapudungun y recopiladores de sus epeu, tales como Tomás Guevara, Sperata de Sauniére, Mayo Calvo, Roberto Lehmann-Nitsche, Bertha Koessler, Sebastián Englert, Yolando Pino, Adalberto Salas, Hugo Carrasco, Yosuke Kuramochi, Juan Adolfo Vásquez... (Carrasco, I. semana 15-17).

Hacia 1970, en la sociedad chilena global se consideraba que la literatura mapuche no existía, argumentándose razones lingüísticas principalmente aunque se podían encontrar obras indigenistas o indianistas y estudios del tema mapuche (todavía llamado araucano). Paralelamente, en ese tiempo en nuestro medio no circulaban todas las teorías literarias y textuales que ahora están a disposición de los estudiosos y en otras disciplinas cercanas (la sociología, la antropología, la filosofía, la estética) y no existían preocupaciones atingentes al estudio de las manifestaciones indígenas equivalentes a la literatura occidental.

Por ello, nadie nos enseñó a leer los textos mapuches y fue inevitable elaborar las categorías teórico-metodológicas necesarias a partir del objeto de estudio supuesto, los escasos textos disponibles, contando obviamente con el intercambio con los escritores que iban apareciendo y con la experiencia directa de su sociedad y cultura. Luego vendría el estudio sistemático de alguna clase de textos en cuanto etnoliteratura y otros como literatura etnocultural, revisitadas hasta hoy, continuado y ampliado por Hugo Carrasco en la Universidad de la Frontera de Temuco (que hizo su Tesis Doctoral sobre el mito mapuche en la Universidad de Chile), en equipo con Verónica Contreras, Mabel García, Teresa Poblete y diversos grupos de trabajo en la UFRO, en los cuales participaron Juan Manuel Fierro, Orietta Geeregat, Sonia Betancour y otros profesores y estudiantes. Ellos ampliaron las investigaciones de la lengua y la literatura mapuche a los mitos, los discursos públicos y políticos, las artes visuales y otras dimensiones socioculturales, editaron dos revistas, Lengua y Literatura Mapuche y Pentukun, organizaron los congresos de Lengua y Literatura Mapuche, hoy transformados en congresos indoamericanos. Esto 
se proyectó transversalmente en la universidad y generó la formación de un centro de estudios indígenas. Todo esto ha convertido a Temuco y a la UFRO en el referente internacional de la cultura verbal mapuche.

También en Temuco, en la Universidad Católica de Temuco se ha realizado un trabajo interesante a partir de 1970 con la realización de las Semanas Indigenistas y la fundación del Centro de Estudios de la Realidad Regional (CERER) por Víctor Raviola; en su revista Stylo se publicaron los primeros trabajos fundados teóricamente sobre la literatura y la etnoliteratura mapuche a partir de 1971; la representante actual de estos estudios es Eugenia Merino, quien ha hecho publicaciones lingüísticas y literarias.

Por otra parte, en la Universidad Austral de Chile, en Valdivia, Claudia Rodríguez, Tesis Doctoral en la Universidad de Oviedo sobre Chihuailaf y Lienlaf, ha ampliado el campo incluyendo a las poetas mapuche y a los poetas indígenas de Sudamérica (Bolivia, Perú, Colombia, Ecuador...157-174; 151163). En la Universidad de Los Lagos, en Osorno, James Park, que hizo su Tesis Doctoral en Estados Unidos también se ha dedicado a la poesía mapuche (139-162), lo mismo que Sergio Mansilla (83-92), Pilar Álvarez-Santullano, Eduardo Barraza, estudian el sector huilliche de esta escritura. En Concepción, Susan Foote y Mauricio Ostria se han interesado en el discurso autobiográfico y la narrativa mapuche. En Santiago, entre otros, Fernanda Moraga estudia algunas poetas desde categorías feministas (225-239), Grínor Rojo, Soledad Falabella, Allyson Ramay, Luisa Eguiluz han hecho aportes interesantes, y recientemente se han incorporado a este ámbito dos especialistas en poesía chilena, Magda Sepúlveda (175-190) y Paula Miranda (191-194).

Hoy día, ya cimentado el campo de la literatura y los estudios mapuche, se despiertan inquietudes de variada índole que surgen sobre los aportes del grupo inicial, respetado, criticado o ignorado por el espíritu competitivo de algunos estudiosos y creadores, como suele suceder. Ha aumentado el número de poetas y están apareciendo los narradores, hay más investigadores y por ende más publicaciones de variada índole, más tesis de pre- y postgrado, ponencias en congresos nacionales e internacionales y preocupación de los medios de comunicación social por esta textualidad nueva en Chile; publicaciones e investigaciones recientes incluyen categorías teóricas e ideológicas provenientes del pensamiento europeo y norteamericano de moda, ampliando y diversificando el objeto de estudio. Pero, al mismo tiempo, creando dudas sobre la pertinencia de algunas categorías, construidas sobre premisas y objetos distintos, para entender las letras mapuches, sobre todo considerando que para estudiar una etnoliteratura o una literatura indígena 
determinada es indispensable la experiencia de sus textos, pero también de su sociedad y su cultura.

Algunos poetas han realizado actividades críticas y divulgativas de su propia escritura, tal como José Ancán, que ha publicado ensayos críticos y estéticos de la poesía y plástica mapuche emergente, Elicura Chihuailaf, que dio su apoyo a escritores y artistas mapuche jóvenes y escribió crónicas sobre su obra, además de artículos en revistas culturales y periódicos, Jaime Huenun, que ha publicado en Chile y España antologías de poesía mapuche, con la colaboración de Luis Ernesto Cárcamo; Adriana Paredes Pinda, que junto con participar en congresos de Literatura, escribió su tesis de Magíster en Literatura en la Universidad Austral de Chile sobre un poeta mapuche y luego su tesis doctoral sobre el rakiduam (2008 y 2013), Maribel Mora, en la Universidad de Chile, que escribe artículos y participa con ponencias en congresos y ha asumido la temática indígena en sus estudios graduados, Pablo Wirimilla, que difunde la literatura huilliche en Internet, etc. También es necesario enfatizar a los docentes e investigadores mapuche de su literatura, como Manuel Segundo Manquepi, mi primer colaborador y maestro (QEPD), María Catrileo y experta en su cultura, Héctor Painequeo, docente e investigador de la versificación de los ül en la Universidad de la Frontera, entre otros más jóvenes.

\section{ANTROPÓLOGO DE LO SUYO}

Profesor y escritor, alejado de la institución literaria, Pedro Alonzo ha publicado libros de poemas, novelas, anecdotarios, poesía popular (con el seudónimo de Vitalicio Ulloa), un manual de Historia y Geografía, cuentos. Descendiente del mestizaje de sus tatarabuelos Juan Alonzo Ñancucheo, lenguaraz, y su esposa Carmen Jaramillo, cautiva de indios, según sus propias palabras. Su libro poético epu mari quiñe ülcatun, publicado a comienzos de la década del 70, en su reedición de 2011 agrega una tilde en "quiñe" (epu mari quiñé), ya que esa acentuación es usada en algunos sectores del habla mapudungun de la zona de la Frontera.

El título global del volumen es unitario en la medida en que señala una imagen de autor único, aunque dual por su situación contextual en la sociedad mapuche lafquenche (de la costa y las playas), que forma parte tanto de la sociedad global mapuche como de la chilena. Dual también es su escritura, porque el libro de poemas forma parte de la cultura occidental asimilada en 
nuestro país, aunque las referencias culturales y una de las lenguas usadas, son mapuche. Por ello, presenta una visión ambivalente, pues no se sabe con claridad si se trata de un mapuche o de un sujeto mapuche ahuincado, aculturado, o un huinca que desea reetnizarse; ambiguos son su nombre y apellidos de origen hispánico, hecho habitual en las comunidades mapuche.

Es un sujeto de doble saber, de doble cultura, un hombre intercultural que además de la cultura y la lengua mapuche posee una cultura básica chilena: maneja la lengua española, sabe historia de Chile, conoce poesía épica, $L a$ Araucana de Ercilla y otros textos. epu mari quiñe ülcatun es un espacio de encuentro intercultural escrito en forma de diálogo en dos lenguas en que declara la condición intercultural de sus abuelos y por tanto de su familia. Todo ello demuestra que el volumen sigue la forma de un informe autoetnográfico.

El título global y los de cada poema están escritos en una lengua, mapudungun, y denotan numeración, "epu mari quiñe" significa "veintiún", pero su uso connota competencia y sentido identitario, un mapuche que sabe contar, hablar y escribir en su lengua. En este caso se refiere a veintiún ülcatún, es decir, a veintiún cantos, quizás cantares, también poemas, entre canto mapuche y poema occidental, dada la asimilación que se ha realizado por parte de los mapuche que manejan su lengua y la de los huinca que la han estudiado. Por ello, estos títulos no niegan el acceso a los textos, pues la numeración en mapudungun es conocida por muchas personas (no así sus matemáticas), aunque enfatizan la mapuchidad, la indigenidad de los personajes que dialogan, aunque ya sea una mapuchidad intercultural o champurria (palabra dicha en la actualidad por algunos mapuche que reconocen y no desprecian su condición actual, en sentidos divergentes del original-mezclado con huinca, ahuincado, aculturado, traidor-despectivo e hiriente).

La particular perspectiva de la enunciación poética de los poemas que conforman el volumen es la de un mapuche asumido, es decir, que reconoce o reasume su condición de tal que había perdido o de la cual no tenía conciencia por motivos de residencia en sectores citadinos, de ocultamiento por necesidad de refugio, protección o por la educación dada por sus propios padres para que no sufriera como ellos por ser mapuche, o por carecer formal o legalmente de nombres o apellidos mapuche. En otras palabras, un ser humano que se asume o reasume como mapuche en todas sus dimensiones, como Rayen Kvyeh, por ejemplo, por tanto, que se etniza o reetniza.

Este sujeto, representado como varón, intenta revitalizar sus vivencias de niño en la comunidad mapuche, para rehacerse completamente, efectuando el periplo inverso al de la emigración de los campesinos chilenos del campo 
a la ciudad para establecerse ahí por pérdida de su residencia por expulsión, cambio de dueño de las tierras o búsqueda de otra forma de vida, en el que se cuenta también un sector indígena. El principal sujeto lírico de los poemas de Alonzo es un hombre que debió irse al pueblo o ciudad cuando niño y que ha iniciado un proceso de recuperación de la identidad mantenida en la memoria, superpuesta a las culturas y lenguas española, chilena y europea, un definido intento de reetnización a través de la poesía.

Estos poemas se conforman de acuerdo al modelo de texto poético etnocultural característico de los escritores de la segunda mitad del siglo XX, constituido por una codificación plural en su variante de collage etnolingüístico, es decir, una mezcla de versos y frases en español y mapudungun, sobre una base en lengua española. Esto último, más el glosario lingüístico del final de todos los poemas (como se verá más adelante) que explica el sentido del léxico mapudungun y las comillas que destacan los términos y frases en esa lengua, es muy significativo debido a su orientación a los hablantes y lectores de español, lo que explicita en otra dimensión su carácter intercultural. A los destinatarios huinca se les informa sobre la vida y la cultura mapuche, carácter intercultural de la situación enunciativa, al modo de una autoetnografía. Pero, al mismo tiempo la presencia de un destinatario mapuche es evidente en la forma apelativa o conversacional con que el hablante básico se dirige al mismo tiempo a sus peñi (hermanos) mapuche, algunos con nombre personal como Huechapán, Collilonco, Cheuque...

El libro etnocultural de Pedro Alonzo es un conjunto de veintiún poemas, que sigue la estructura de un texto autoetnográfico, a veces en la totalidad del poema, otras en una parte significativa de él. En su conjunto describe aspectos diferentes de los conocimientos de los mapuche sobre su propia vida y cultura, desde la perspectiva de una persona que ha abandonado la comunidad, pero desea recuperar el uso perfecto de la lengua, base de la identidad mapuche. ¿Cómo podrá hacerlo?... Mediante la relación con sus peñi que sobreviven en su entorno originario frente al embate de la modernidad. Si pretende aprender de nuevo, es porque no es un sujeto unidimensional sino por lo menos bidimensional, lo que reconoce al pedirle a su amigo Ignacio que le re-enseñe mapudungun:

Tú me vas a enseñar

"mapu-dungun"

Ignacio Huechapán.

Yo quiero saber, de nuevo, 
lo que dices cuando estás borracho/.../

Nos conocimos "pichichegñeiyu /.../

Desde siempre nos llamábamos "peñi",

y cada vez que el tiempo nos juntaba:

-“fta cuifi, peñi Ignacio, chumuleimi...?

Pero yo me fui lejos

y tú te quedaste debajo de la lluvia

mientras tu ruca fumaba

interminablemente su "pitrén".

Pero voy a volver de nuevo /.../

y tú,

palabra a palabra

me vas a recordar el "mapu-dungún"

que los años han llenado de olvido ("Quila").

El mapudungun por reaprender simboliza la identidad étnica añorada y semidisuelta por la interacción con la sociedad huinca. Por ello, los poemas conforman una serie de autoetnografías que la representan, destinada a los mapuche que los lean para revitalizar o recuperar sus creencias, y a los huinca para que los respeten. De este modo, "Purra" es un diálogo entre jóvenes que incluye informaciones específicas sobre alimentos de mar y tierra, "Ailla" describe un espacio muy adecuado donde ir a mariscar, "Mari Epu" es un análisis detallado de los elementos básicos de la cocina de una abuela, "Mari Kechu" es principalmente el retrato de un mapuche costero, "Mari Cayu", un cuadro de costumbres de un embarcadero, "Mari Purra", la descripción mítica de una montaña donde nació Trununñan, quien luchó contra los españoles y al morir se convirtió en un río, "Quechu", el cortejo que le hace un joven enamorado a una hermosa doncella, "Epu Mari" es el modo de luchar contra las sequías mediante las rogativas que hacen los mapuche, para colocar algunos ejemplos.

Lo interesante es que todas estas semblanzas se refieren a habitantes de un lugar determinado del territorio ancestral de los mapuche, por lo cual la figura retórica que unifica el conjunto de veintiún textos es la descriptio, dado que se trata de una serie de autoetnografías. La última, que citaremos en su totalidad, en apariencia es un cuadro estrictamente mapuche porque dialogan sujetos que manejan el mapudungun, pero ellos no están solos; entre otros indicios, la palabra "reducciones" nos permite inferir que esta comunidad mapuche es un sector de una sociedad global más amplia, dentro 
de la cual ellos están dominados y controlados. En otras palabras, se trata de dos sociedades en contacto, lo que desde una perspectiva intercultural implica que inevitablemente estarán sometidas al cruce y fusión de sus respectivas culturas.

"¿Chem kurruf amulei, Lonconao?

Ya ser masiao largo el sequía..."

El invierno había recogido temprano sus velámenes

y la primavera arribó despejada

sin bordar mariposas sobre el verde.

“CChumulchei mauaful?”

"Gñenualu maun kechilei".

En las lomas los trigos languidecen, no ha crecido la espiga esperanzada. El sol está quemando el pan y el fantasma del hambre anda en el viento.

En las vegas las chacras se silencian; lluvia, se llama la palabra mágica.

-"Nguillatuain mai"

El paisaje es de color ceniza.

Sólo en el pitrantal alumbran los mallines.

-“Muleai quiñe nguillatún".

$\mathrm{Al}$ anochecer suena el cultrún $\mathrm{Y}$ todas las distancias comprenden el llamado.

“-Nguillatún muten montulaein meu”.

Los "rehue" ganan estatura

con las ramas de los canelos agregadas

y la noche entera es un mensaje

de loma en loma

hasta las últimas "reducciones".

-En el alto de Malalhue será el nguillatún.

Las rogativas no terminarán 
mientras desde el mar

no cambie de color los limpios cielos

No importan los días,

no importa el cansancio del baile interminable,

pero nadie dormirá,

nadie probará bocado alguno,

hasta cuando "Huenuchao" haya oído

y nuble su alto cielo

y entregue las monedas de la lluvia.

epu mari

veinte

chem kurruf amulei ¿qué viento sopla?

chumulchei mauafuy ¿Cuándo lloverá?

gñenualu maun kechilei no hay esperanza de lluvia

nguillatuain mai hay que hacer nguillatún

muleai quiñe nguillatún es necesario un nguillatún nguillatún muten montulaein meu solo nos salva un nguillatún rehue Altar

Aquí la identidad mapuche se establece en relación con la sequía, el debilitamiento de la madre tierra y la necesidad del ritual ancestral para recuperarla y fortalecerla una vez más. El texto poético se desarrolla mediante el diálogo exclusivo entre dos mapuche, el joven que viene desde la ciudad y el que sigue viviendo en su tierra, Lonconao, como manifestación de la hermandad que los une y que mantiene invisible e incomunicado al otro, al huinca; éste es tratado como objeto y no como sujeto enunciativo. Por ello no aparece explícito en éste y en la mayoría de los otros poemas, los interlocutores dialogan entre sí y ni siquiera lo aluden porque es el invasor de la tierra y, al no hablarle, se le ignora; además, por la diferencia cultural, buscaría una solución técnica para disminuir o resolver los efectos de la sequía en lugar de recurrir a las machi del lugar.

El poema se inicia desde el título, "Epu Mari", y la pregunta inicial sobre el viento que sopla para poder pronosticar la posibilidad de lluvia, ambos en la lengua indígena predominante en Chile; pero, de inmediato se entrelaza con una frase en español "mapuchizado" y otras en español, como una literatura etnocultural. Al mismo tiempo se establece el tipo de discurso esperable, 
la autoetnografía sobre la sequía, sus consecuencias y las posibilidades de superarla mediante las fuerzas de lo sagrado. Es cierto que se describe primero la naturaleza, lo que es obvio, pero es necesario observar que ésta aparece dominada por la imagen y la prosopopeya, que la transforman en cultura: "El invierno había recogido temprano sus velámenes", la primavera arribó "sin bordar mariposas sobre el verde", "el sol está quemando el pan", "el fantasma del hambre anda en el viento", etc., hasta que se hace necesario llamar a nguillatún. Éste aparece caracterizado a través de elementos culturales que lo constituyen, el cultrún, el rehue, el baile, Huenuchao, la espera de las "monedas" de la lluvia, el mundo simbólico: "la noche entera es un mensaje".

Sin duda, la sequía es el tema principal, desarrollado y sugerido en este poema, causa del hambre, la pobreza, la dependencia, el desánimo, la preocupación de estas personas. Pero también es símbolo de la comunidad mapuche lafquenche, que sufre la sequía de su existencia, su presente, su porvenir, su identidad, que siente cómo su condición indígena se deshace como el pasto, los sembrados, los animales, por la ausencia de agua, de esperanzas, de posibilidades de vivir y trabajar en las tierras que fueron de sus antepasados, es la sequía de los sueños, las tradiciones, la lengua que se marchita, la vida que es quemada por el sol o se hiela y agoniza en las noches de frío, pobreza y abandono.

¿A quién se le pregunta por el futuro inmediato, si lloverá o no?... Sin duda, a Lonconao que es un informante privilegiado, que se la ofrece a su vecino, el sujeto lírico que desea reconvertirse en mapuche y por ello asume una doble condición, a veces hablante, otras destinatario, en su diálogo incesante. Por ello este sujeto es también otredad en medio de los suyos, lo mismo quizás que Juan Antillanca. El poema autoetnográfico permite comunicarse entre hermanos, entre semejantes, en este caso el sujeto lírico, que es un hombre mapuche, apostrofa a Lonconao para que por su mayor edad y competencia cognitiva en su propia cultura, describa y explique la situación de la tierra y de las personas que allí viven durante un período de sequía extrema, estimulándolo mediante preguntas en su lengua común: ¿Chem kurruf amulei, Lonconao? ¿Chumulchei mauaful?

Por lo tanto, Lonconao es oyente cuando su peñi recurre a él con desesperación para encontrar una solución y hablante cuando le responde, lo mismo que sucede con su interlocutor, ambos son destinador y destinatario, consultor e informante, recíproca y alternativamente. En otras palabras, los dos actúan asumiendo los roles de huinca que quiere aprender y de indígena que sabe y acepta compartir su saber, son el otro y el mismo. 
Ésta es la situación central de este poema autoetnográfico, factor cognitivo, porque permite solicitar y recibir conocimientos de carácter tradicional, testimonial y autobiográfico que pocos conservan en una comunidad que agoniza con lentitud y angustia. Pero, al mismo tiempo, una expresión literaria, estética, que es mucho más que una textualidad práctica y racional, porque no solo se refiere a una situación referencial y semántica, sino también expresa el estado de ánimo, las sensaciones y emotividad de los indígenas que ven agonizar junto con su mapu.

Pero, dado que el poema es un texto que se ha generado en la cultura huinca como un acto de escritura de cierto tipo, artístico literario, y que su contenido semántico es conocido a fondo por los indígenas pero no necesariamente por los demás habitantes del mismo territorio, resulta evidente que su principal destinatario indirecto lo conforma el sector de personas que no siente suyas las formas de vida, lengua, cultura, mapuche que es huinca pero también ahuincado. Este texto es un modo de mostrar lo que se es y se tiene, a los otros, que son y tienen cosas distintas, de lo que se desprende una actitud bélica, separatista, utópica, pero también pacífica, integrativa y utópica, en la medida en que acepta, propone o intenta realizar la utopía del diálogo en el difícil equilibrio de aceptar el pasado y establecer caminos concordantes válidos para todos hacia un futuro inestable.

Y ello nos permite comprender que el texto sobre la sequía es, desde una perspectiva antropológica, un conjunto de conocimientos determinados sobre una etnia y una cultura en un momento de su devenir histórico, en aculturación, lo que coincide con la literatura antropológica que cumple funciones, de conocimiento, pero al mismo tiempo para crear una modalidad de expresar, manifestar, sentir, gozar, suponer, etc., en otras palabras, de vivir una experiencia estética particular, intercultural e interétnica.

Frente a la identidad tradicional se encuentra también la sustitución de ella por alguna de las identidades de los colonizadores, europeos o chilenos, este fenómeno o proceso de aculturación es general y todos los chilenos, mapuche y extranjeros aunque lo nieguen, saben que lo son. El sujeto lírico parte de la suposición que va a recuperar la identidad anterior, lo que es una utopía, pues aun viviendo en el mapu también se ha transformado. Pretende mantener una identidad tradicional que supone la permanencia de los valores, los sujetos, la lengua, la vida misma, ignorando que la relación intercultural en que vive lo ha transformado a él y a los demás. Aquella identidad esperada y buscada solo existe parcialmente. 
La conformación del enunciado etnocultural del texto poético configura sujetos interculturales y con ello un mundo plural, borrando para siempre la ilusión de ser absoluta y únicamente mapuche o huinca. O mejor dicho, el modo de ser mapuche ahora es también intercultural. El tiempo que ha pasado el hablante fuera de la ruca le sugiere que ello no es posible, a pesar de su amor a la tierra y sus tradiciones identitarias.

Los dos amigos representan a la comunidad ancestral existente en su memoria, definida por un ansia de continuidad, de persistencia, comprensible para seres que han sido expoliados y despojados de su mapu y obligados a vivir en un mundo mestizo en que han perdido todo: la identidad, la cultura, el sustento. Sin embargo, en ellos persiste la esperanza de recuperar el mapu, el espacio sagrado (en palabras de Eliade 19-56), para reconstruir el pasado perdido.

La oposición a esta perspectiva se encuentra en el poema "Mari Ailla", concentrado en el concepto de "ahuincarse", fenómeno muy mal visto por todos, particularmente por los ancianos, pues se relaciona con "huinca", es decir, extranjero, blanco, enemigo. Mientras otros poemas se refieren a hechos distintos, como costumbres, lugares, rituales, personajes característicos, formas de hablar, etc., que contribuyen a afianzar la identidad tradicional mapuche, este poema enrostra a un peñi por haberse transformado en un enemigo de la raza, asumiendo un rol y un estatus perjudicial para él mismo y para sus hermanos mediante la transformación de su de modo de ser y de vivir. La crítica es para Juan Antillanca, porque ha asumido un rol de huinca, más todavía, defensor de la ley huinca, por lo tanto va a ser ahuincado, es decir, un sujeto híbrido, detestable, peligroso.

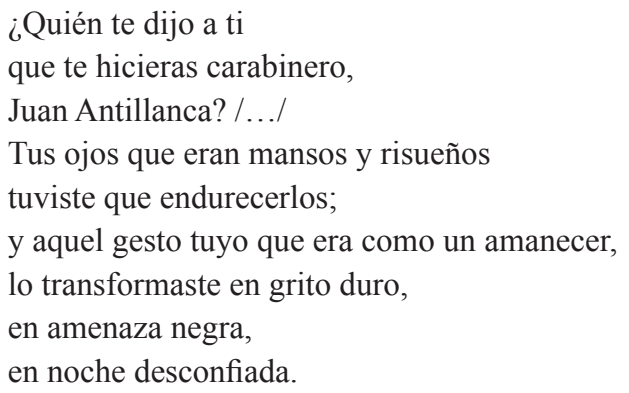

La escena es clara: el sujeto central del libro, que dialoga con los demás protagonistas para mostrar los distintos aspectos de la sociedad mapuche, 
enrostra a un hombre que debe olvidar su pasado y asumir un nuevo estatus y un nuevo rol social para ganarse la vida. Pero, el rol y el estatus forman parte de la cultura huinca y no mapuche, además que contribuye a causar dolor a sus integrantes. Juan Antillanca es acusado de ser inconsecuente, ya que debió robar para tener algo de comida, pero ahora debe buscar y perseguir a los que roban ovejas por hambre y por falta de trabajo. Quien debió sufrir la muerte de su padre en un cuartel debe olvidar a los suyos para cumplir sus funciones policiales. Sus peñi le enrostran que fue elegido carabinero porque es mapuche, es decir, habla mapudungun y conoce su territorio, elementos necesarios para perseguir mejor a los "delincuentes". Y ellos no solo lo saben, sino también lo divulgan y comentan con acritud y dolor:

Antillanca se hizo carabinero

Para ganar el pan pescando presos a sus hermanos.

El lenguaje del sujeto poético, que repite las palabras de su comunidad, se ha hecho prosaico y violento, pues la herida no es solo para sus amigos sino también para toda la etnia. El epifonema que culmina el texto es indirecto y metafórico, para que duela más y deje pensando a ese hermano que ahora es un extraño y un traidor, un ser ajeno a su origen y su propia identidad: es la otredad misma:

¿Qué gusto tiene ese pan, Antillanca?

El enunciador lo establece como un conflicto, una oposición, un contraste entre la identidad común de los mapuche, concebida como única, positiva, superior, y la de los otros, los huincas, conformada por rasgos diferentes y opuestos. Tanto el hablante como Juan Antillanca son de la misma condición, por lo cual la otredad son los enemigos, los huinca y su carga de opresión, destrucción, muerte social y cultural. Ellos han transformado a Antillanca en una nueva otredad, ahora ya no de los huinca, sino de los mismos mapuche. Por eso, el sujeto enunciador también cambia su visión, se convierte en un observador, investigador de sí mismo, de su peñi Juan Antillanca que ahora ya no es el mismo, sino el otro, el malvado, el enemigo. Pero sigue siendo mapuche. Por tanto, la ambivalencia cubre también a lo mapuche. Y al ser observador de sí mismo y de lo mismo, su poema conforma una autoetnografía.

Lo mismo sucede en la mayoría de los demás textos del volumen. Los dos primeros y el último confirman la identidad antigua, bélica y culturalmente confrontada con la otra, la europeo-hispánica llegada con la invasión española; 
los poemas siguientes son pequeñas autoetnografías de la cotidianidad mapuche lafquenche. Como escribió Acevedo en el Prólogo, “... lo medular del libro está en los pequeños hechos de la vida del mapuche actual evocados por el autor; sus faenas, la miseria, la amistad, la explotación de su trabajo, sus esperanzas, sus temores"... (1970: 5).

En efecto, el poema "Quila", como hemos visto, inicia el desarrollo de la identidad mapuche, en particular lafquenche, desplegada a través del valor del mapudungun y de la amistad. Este poema puede considerarse, entonces, la base temática e ideológica del volumen, la confirmación de la identidad propia tradicional. A continuación se desarrolla principalmente el cuadro económico y de la pobreza, considerada como rasgo de la identidad mapuche en algunos períodos (Stuchlik 26-50); en particular conmueve en "Meli" la figura de Millalonco, su grupo familiar y sus visiones, o de Cantalicio Millavil, "Cuando te conocí,/ ya eras viejo y ya eras pobre./Tú naciste pobre" ("Mari Quila"). Éste es continuado en la descripción y explicación de la recolección de alimentos, la pesca, la cocina de la abuela, la vejez, la destrucción de la familia, las secuelas de la sequía, la explotación de su trabajo, etc. Por otra parte, sobresale la descripción de ciertos seres y costumbres, como el flirteo y el amor, la visita al pueblo, los seres sobrenaturales positivos y maléficos, el mundo simbólico y religioso, la mitificación de los guerreros, el nguillatún y otros rituales, la percepción del tiempo, la aculturación, la historia, en la que destaca el nacimiento de Arauco, etc.

Una de las estrategias principales de los poemas es el apóstrofe a un destinatario lírico determinado, a quien un sujeto le consulta o solicita algo, además de permanentes preguntas retóricas, clara muestra de la dialogicidad mapuche; los destinatarios son los habitantes de la comunidad lafquenche y tienen un nombre huinca y un apellido mapuche, como Juan Levío, Ramón Cheuque, Copihue Millalonco, señal inequívoca del mestizaje etnocultural, o son llamados por su único nombre en mapudungún, Paineo, Ñancupil, Colillonco, para sugerir su sentimiento de vecindad y afecto.

\section{CONCLUSIONES}

La originalidad de los textos de Pedro Alonzo en el conjunto de la poesía etnocultural de cultura mapuche reside en la presentación de la situación de inculturación voluntaria, inversa a la que ocurre por lo general en la sociedad rural del sur de Chile, en que muchos mapuche se ven obligados a adoptar 
costumbres, identidades, lenguas, en suma, culturas y modos de ser no indígenas, para sobrevivir en la ciudad, debiendo muchas veces abandonar también sus tierras y con ello romper el contacto con la ancestralidad.

Alonzo ha elaborado sus poemas como una serie de informes autoetnográficos sobre ámbitos determinados de una zona mapuche contemporánea, una comunidad lafquenche, que al parecer se conserva desde la llegada de los españoles, soportando los cambios históricos, culturales, lingüísticos, interactuando con los huinca y formando parte de una historia común, aunque soportada y evaluada desde parámetros opuestos. En la configuración de sus poemas usa la estrategia de la codificación plural en su variante de collage etnolingüístico, serie de enunciados en mapudungun y en español, presentados de modo yuxtapuesto que representan las diferencias identitarias, culturales y lingüísticas individuales. Así, los discursos de variados sujetos aparecen integrados en la unidad mayor del poema, igual a la interacción cotidiana de los habitantes de origen mapuche y huinca también aculturados en la sociedad global.

El tipo de sujeto poético presentado es siempre un hombre de etnia y condición mapuche que habla sobre alguna dimensión de su cultura, explicándosela a otros, actitud de etnógrafo que actuando como investigador analiza en detalle algunos aspectos, pero manteniéndose separado en cierta medida, es decir, como un "observador participante", pues forma parte de ese mundo aunque no es de él. Y por ello hay un cierto rigor en la observación, porque viene y mira desde otro lugar, al tiempo que lo describe para otros, por lo cual es una forma de autoetnografía. Y, al ubicarse de este modo ambivalente y ambiguo, mira su realidad como una otredad y por ello configura al destinatario como un dialogante con sus semejantes y extraños. En otras palabras, su disposición es la de un antropólogo de sí mismo que escribe sus informes (poemas) destinados a sus hermanos mestizos, usando un tipo de texto autoetnográfico de carácter literario.

Por ello, su postura no es la de un antropólogo que pide información a seres de otra condición étnica y cultural, de un extranjero que quiere conocer un mundo que no le pertenece, sino la de un hombre que posee una cultura identitaria básica que se ha debilitado, por lo cual espera recuperarla en el diálogo con sus semejantes, pero que también ha mutado como él mismo, siendo no solo compañeros de comunidad sino también otros, extraños. Y por ello no puede integrarse sin cumplir el ritual del acceso a la comunidad que es el manejo de la lengua propia acompañado por sus peñi. Y por ello, 
siendo extraño que se reincorpora a lo que quiere ser, asume la actitud de un investigador de lo propio, un antropólogo de sí mismo.

\section{BIBLIOGRAFÍA}

Alonzo Retamal, Pedro. epu mari quiñe ülcatun. Temuco: Imprenta y Editorial San Francisco, 1970; 2a . ed. Valparaíso: Impresos El Mercurio de Valparaíso. "Prólogo" de Orlando Acevedo V. e "Informe de Lectura" de I. Carrasco M., 2009.

Augé, Marc. El sentido de los otros. Actualidad de la antropología. Traducción de Charo Lacalle y José Luis Fecé. Barcelona: Paidós, 1996.

Bogatyrev, Petr y Roman Jakobson. "Le folklore, forme spécifique de création”. En R. Jakobson Questions de Poétique. Paris: Editions du Seuil, 1973. 59-72.

Carrasco, Hugo. El mito de Shumpall en relatos orales mapuches. Tesis de Magíster en Literatura M/ Teoría Literaria. Universidad Austral de Chile, 1981.

Carrasco M., Iván. Interculturalidad "Literatura intercultural chilena: proyectos actuales". Revista Chilena de Literatura 66 (2005): 63-84.

Textos "Los textos de doble codificación. Fundamentos para una investigación". Estudios Filológicos 26 (1991): 5-15.

Notas. "Notas introductorias a la literatura mapuche". En Víctor Raviola (Ed.). Tercera Semana Indigenista. Temuco: Ediciones Universitarias de la Frontera, 1972. 15-23.

Eco, Umberto. "Semiótica y cultura". Cultura y semiótica. Traducción de Mario León y Consuelo Vásquez de Parga. Madrid: Círculo de Bellas Artes, 2009. 27-53.

Eliade, Mircea. Lo sagrado y lo profano. Traductor Luis Gil. Madrid: Guadarrama, 1981. $4^{\mathrm{a}} \mathrm{ed}$.

Falabella, Soledad; Allison Ramay y Graciela Huinao. Hilando la memoria. 7 mujeres mapuche. Santiago: Cuarto Propio, 2006.

García B, Mabel. "El proceso de retradicionalización cultural en la poesía mapuche actual: ÜI de Adriana Paredes Pinda". Revista Chilena de Literatura 81 (2012): 51-68.

Grebe, María Ester. "Etnopoética: Un replanteamiento antropológico del arte". Aisthesis 15 (1983): 19-27.

López-Baralt, Mercedes. Para decir al Otro. Literatura y antropología en nuestra América. Madrid: Iberoamericana-Vervuert, 2005.

Mansilla, Sergio. "Escrituras etnoculturales: ¿escribir con o contra el otro? (en torno a la poesía chilena etnocultural en la Xa. Región de Los Lagos)". En Pilar Alvarez-Santullano y Amílcar Forno. Fütawillimapu. CONADI Décima Región de Los Lagos/ Universidad de Los Lagos, 2001. 83-92.

Miranda, Paula. “Alé. Luz de la Luna. María Isabel Lara Millapan”. Taller de Letras 52 (2013): 191-194.

Moraga, Fernanda. “A propósito de la "diferencia”, poesía de mujeres mapuche". Revista Chilena de Literatura 74 (2009): 225-239. 
Paredes Pinda, Adriana. Epu rume rakizuam: desgarro y florecimiento. La poesía mapuche entre lenguas. Tesis Doctorado en Ciencias Humanas. Universidad Austral de Chile, 2013. Prof. Patrocinante Iván Carrasco M.

Heterogeneidad e hibridismo cultural en la poesía de César Millahueique. Tesis de Magíster en Literatura Hispanoamericana Contemporánea. 2008. Prof. Patrocinantes Óscar Galindo V. - Claudia Rodríguez M.

Park, James. "Discursos y poética mapuche-huilliche actual: cambio generacional y diferencia territorial". Alpha 24 (2007): 139-162.

Rocha Vivas, Miguel. Palabras. Palabras mayores, palabras vivas. Tradiciones mitico-literarias y escritores indígenas en Colombia. Bogotá: Alcaldía Mayor de Bogotá, Secretaría Distrital de Cultura, Recreación y Deporte, Fundación Gilberto Azate Avendaño, 2010a.

Pütchi. Pütchi Biyá Uai. Precursores. Antología multilingüe de la literatura indigena contemporánea en Colombia. Bogotá: Alcaldía Mayor de Bogotá, Secretaría de Cultura, Recreación y Deporte, Secretaría de Educación, Fundación Gilberto Alzate Avendaño, Volumen 1, 2010b.

Rodrigo A., Miquel. La comunicación intercultural. Barcelona: Anthropos Editorial, 1999.

Rodríguez, Claudia. "Los espacios de la poesía indígena: agenciamientos y metatextos". Taller de letras 52 (2013): 157-174.

"Weupifes y machis: canon, género y escritura en la poesía mapuche actual". Estudios Filológicos 40 (2005): 151-163.

Schmidt, Siegfried J. "La comunicación literaria”. En José Antonio Mayoral (comp.). Pragmática de la comunicación literaria. Madrid: Arco/Libros, 1999.

Sepúlveda, Magda. "La palabra chileno nada puede expresar: poesía de origen mapuche". Taller de Letras 52 (2013): 175-190.

Stuchlik, Milan y Adalberto Salas. Rasgos de la sociedad mapuche contemporánea. Modo, persona y número en el verbo mapuche. Santiago: Ediciones Nueva Universidad, 1974. 